\title{
CONSEQUÊNCIAS JURÍDICAS DA REPRODUÇÃO ASSISTIDA HETERÓLOGA
}

\section{Natalie Cafruni di Giorgio ${ }^{1}$}

\section{INTRODUÇÃO}

Dentre as relações de parentesco, a filiação é o mais importante e sólido vínculo de união entre as pessoas, ${ }^{2}$ devendo, assim, ter especial atenção dentro do sistema jurídico. Afinal, por meio da parentalidade e da filiação é que se constrói o vínculo de perpetuação da família.

Através dos nossos filhos que construímos gerações e trocas de aprendizado. Somente a parentalidade irá proporcionar o maior e mais sólido vínculo que o ser humano pode expe- rimentar, qual seja, a relação de carinho, cuidados, troca de ensinamentos e principalmente de afeto - entre pais e filhos.

A filiação, conceituada como a relação de parentesco que se estabelece entre pais e filhos, ou ainda, designada, do ponto de vista dos pais, a relação estabelecida como relação de paternidade e maternidade, ${ }^{3}$ hoje referida como parentalidade por alguns autores, ${ }^{4}$ não é tratada, atualmente, como um mero vínculo consanguíneo.

No atual Direito de Família, consagra-se a concepção de que até mes-

1 Advogada especialista em Direito Processual Civil.

2 RIZZARDO, Arnaldo. Direito de Família. Rio de Janeiro: Forense, 2011. p. 338.

3 BOEIRA. José Bernardo Ramos. Investigação de Paternidade. Posse de Estado de Filho: Paternidade Socioafetiva. Porto Alegre: Livraria do Advogado, 1999. p. 29.

$4 \mathrm{O}$ autor adota o termo "Parentalidade" que para melhor descrever a relação entre pais e mães para com seus filhos. CASSETTARI, Christiano. Multiparentalidade e Parentalidade Socioafetiva: efeitos jurídicos. 2. ed. São Paulo: Atlas, 2015. p. 9 e ss. 
mo o puro afeto pode criar relações jurídicas de parentalidade, conhecidas como vínculos de filiação sociafetiva, qual seja, aquela filiação em que não existe qualquer vínculo biológico com o pai ou a mãe, todavia, existe posse de estado de filho.

Ultrapassadas barreiras biológicas pelo Atual Direito de Família, em que os filhos seriam somente aqueles com ligação consanguínea, valioso referir que com as inovações trazidas pela ciência, criaram-se, nas novas formas de concepção, que o filho não detém, necessariamente, vínculo biológico com os pais.

Se possibilitou, mediante reprodução assistida, novas formas de reprodução, inovadoras, as quais atingem circunstancialmente as antigas concepções de estrutura familiar, as quais, por nítida necessidade, receberam tratamento legislativo especial.

A reprodução assistida heteróloga, tema deste artigo, é o clássico caso de filiação socioafetiva, eis que, pelo menos um dos familiares do núcleo básico - pai e mãe - não terá vínculo sanguíneo com a criança, estabelecendo com ela somente um status de familiae, uma posse de estado de filho, que garantirá a proteção jurídica da relação paterno-filial ou materno-filial por meio da socioafetividade.

Ainda, além do vínculo afetivo, a filiação proveniente da reprodução assistida heteróloga ainda detém uma presunção de parentalidade, conforme será estudado.
Sendo a filiação questão essencial ao Direito de Família, com as transformações sociais pertinentes a cada momento histórico, seu disciplinamento legal obteve significante evolução legislativa no Brasil, refletindo as questões sociais pertinentes ao núcleo familiar.

Apesar do tratamento legislativo próprio dado a este tema, por ser tão novo e científico, a expressividade da legislação própria sobre o tema é fraca, eis que a reprodução assistida heteróloga somente aparece no sistema jurídico brasileiro em duas leis - Código Civil de 2002 e nas Resoluções Médicas que regulamentam a Reprodução Assistida, ou seja, o tema se encontra pouco regulamentado.

Este artigo visa levantar dúvidas e tentar encontrar as soluções pertinentes ao tema, no que tange às relações socioafetivas criadas com o cônjuge não doador, e que ainda estão em aberto, tais como a extensão da presunção de paternidade constante no Código Civil para uniões estáveis, a possibilidade de presunção de maternidade em casos que o não doador seja o cônjuge virago, ou ainda, até mesmo a discutida possibilidade de investigação de paternidade/maternidade para fins genéticos, entre outros conteúdos pertinentes.

A fim de responder tais questões, necessária uma evolução legislativa da asserção, bem como igualmente necessário que se discorra sobre so- 
cioafetividade e sobre as principais técnicas de reprodução assistida atualmente utilizadas.

\section{BREVE HISTÓRICO}

Diante das novas estruturas familiares regulamentadas nas últimas décadas, é de se referir que a filiação é um estado, que se trata de um status familiae, exprimindo uma relação filial construída mediante nascimento biológico - dos pais que realmente 0 geraram ou não. ${ }^{5}$

Assim, filiação é o vínculo consanguíneo entre filhos e pais, chamada de filiação biológica, bem como o vínculo socioafetivo proveniente da posse de estado de filho em relação à figura paterna ou materna, sem que exista qualquer relação consanguínea.

Todavia, nem sempre este foi o tratamento dado ao tema. A evolução histórica do Direito de Família, na legislação brasileira, apresentou profundas modificações no que tange ao tratamento dos filhos entre o Código Civil de 1916 e a promulgação da Constituição Federal de 1988, sendo necessária sua abordagem.
Inicialmente, tem-se como marco de evolução legislativa a Lei n. 4.737 de 27.09.1942, que em seu artigo primeiro permitiu o reconhecimento do filho havido fora da constância do casamento após o desquite do genitor, seguida da Lei 4.883 de 21.10.1949, abrangendo para tanto para qualquer um dos pais, tanto para o filho, a possibilidade de reconhecimento da filiação, através de ação declaratória própria. ${ }^{6}$

A partir do advento da Lei do Divórcio, Lei n. 6.515 de 26.12.1977, surgiu a garantia a todos os filhos do direito à herança, em igualdade de condições, existindo até mesmo a previsão de reconhecimento do filho fora do casamento por meio de testamento cerrado, ainda que na constância do casamento, reconhecimento este a ser dado por qualquer um dos cônjuges.

A partir de então, todos os filhos ilegítimos poderiam ser registrados, por mais que ainda permanecesse vigente, no Código Civil de 1916, o artigo 358, que vedava o reconhecimento dos filhos incestuosos, o qual só veio a ser revogado com a Lei n. 7.841 de 17.10.1989. ${ }^{7}$

Expressiva modificação (não apenas no Direito de Família, mas no

5 VENOSA. Sílvio de Salvo. Direito Civil: direito de família. São Paulo: Atlas, 2008. p. 342.

6 RIZZARDO, Arnaldo. Op. cit., p.339.

7 DIAS, Maria Berenice. Manual de Direito das Famílias. Porto Alegre: Livraria do Advogado, 2005. p.327. 
panorama jurídico em geral), contudo, surgiu apenas com a Constituição Federal Brasileira de 1988. A Carta Magna de 1988 igualou os direitos entre homem e mulher, reconheceu a união estável e proteção a todos os tipos de família, bem como a mudança mais pertinente ao nosso tema, consagrou igualdade entre filiações. ${ }^{8}$

Seguindo as novas constituições democráticas do século $\mathrm{XX}$, como a espanhola de 1978, entre outros países europeus tais como França, Itália, e Alemanha, que abandonou a influência do Código de Napoleão no que se refere à filiação (que discriminava os filhos que eram concebidos fora da constância do casamento, não existindo isonomia de tratamento jurídico entre as filiações), ${ }^{9}$ a Constituição Federal de 1988 ultrapassou as denominações de prole legítima ou ilegítima.

Desse modo, todos os filhos são considerados iguais, especialmente em razão do artigo 227, $\S 6^{\circ}$ da Constituição Federal de 1988, tendo todos os mesmos direitos e as qualificações, proibida qualquer discriminação entre estes.

Ao vedar o tratamento discriminatório dos filhos, pode-se referir que a nova Carta Magna consolidou o afeto como elemento de maior importância, introduzindo-se na Constituição o que estava sendo reconhecido na doutrina, na lei especial e na jurisprudência, ${ }^{10}$ indo de encontro com antigas premissas que regulavam a família tradicionalmente matrimonial e unida unicamente pelo parentesco consanguíneo, incluindo, assim, na filiação, o afeto como centro das relações formadas entre pais, mães e filhos.

Seguindo os mesmos passos no referente aos tratamento expendido com os filhos, o Código Civil de 2002 transmitiu a regra constitucional da igualdade entre filiações e acrescentou alguns dos avanços científicos das últimas décadas, tratando, ainda que timidamente, sobre reprodução assistida.

Valioso mencionar que não há menção expressa sobre a filiação socioafetiva ou sobre o afeto como norteador das relações familiares, apesar de ser amplamente tratada e aceita pela jurisprudência e doutrina.

Ainda no que tange ao ordenamento jurídico da filiação presente no Código Civil, apesar de muito criticada, permaneceu vigente a filia-

8 FACHIN, Luiz Edson. Elementos Críticos de Direito de Família. Rio de Janeiro: Renovar, 2003. p. 17.

9 GONZALES, África; DIAS, Maria Berenice (coord.). Afeto, Ética, Família e o Novo Código Civil. Belo Horizonte: Del Rey, 2004. p. 22.

10 FUJITA, Jorge Shiguemitsu. Filiação. São Paulo: Atlas, 2011. p. 22. 
ção jurídica, atribuindo a paternidade por força do casamento, chamada de pater is est, proveniente da máxima romana "pater is est quem nuptiae demonstrant”, que nada mais é que a presunção de que a paternidade será sempre do marido da mãe. ${ }^{11}$

Tal disposição estabelece que são presumidos os filhos nascidos 180 (cento e oitenta) dias depois de estabelecida a convivência conjugal, 300 (trezentos) dias subsequentes a dissolução do casamento, os havidos por fecundação artificial homóloga, mesmo que falecido o marido e proveniente de embriões excedentários, e por fim e mais importante para o tema que tratamos, os havidos por inseminação artificial heteróloga, desde que com autorização prévia do marido.

A filiação jurídica é herança do Código Civil de 1916 que veio a ser mencionada no Código Civil de 2002, estando presente em outros ordena- mentos jurídicos, tais como o Código Civil Francês, O Código Civil Suíço e o Código Civil Argentino. ${ }^{12}$

Vale salientar, contudo que com as técnicas de reprodução assistida e de investigação de paternidade, em que se oportuniza o exame ácido desoxirribonucleico (DNA) acabaram por modificar substancialmente a presunção de paternidade, ainda que esta continue constando no Código Civil de 2002, ${ }^{13}$ no artigo $1.597 .{ }^{14}$

No que tange a regulamentação sobre reprodução assistida, apesar de todo avanço legislativo aqui demonstrado esta continua quase sem legislação específica, tendo como base somente algumas determinações do Código Civil e da Resolução n. 2013/2013, do Conselho Federal de Medicina.

Desse modo, denota-se que a legislação concernente à filiação ultrapassou diversos dogmas e foi amplamente modificada nas últimas décadas,

11 BOEIRA. José Bernardo Ramos. Op. cit., p. 41.

12 Idem.

13 FUJITA, Jorge Shiguemitsu. Op. cit., p.62

14 "Artigo 1.597. Presumem-se concebidos na constância do casamento os filhos: I. nascidos cento e oitenta dias, pelo menos, depois de estabelecida a convivência conjugal; II. nascidos nos trezentos dias subsequentes à dissolução da sociedade conjugal, por morte, separação judicial, nulidade e anulação do casamento; III. havidos por fecundação artificial homóloga, mesmo que falecido o marido; IV. havidos, a qualquer tempo, quando se tratar de embriões excedentários, decorrentes de concepção artificial homóloga; V. havidos por inseminação artificial heteróloga, desde que tenha prévia autorização do marido" (BRASIL, Lei n. 10.406, de 10 de janeiro de 2002). 
podendo, atualmente, subdividir-se as filiações quanto a sua natureza, em filiação jurídica, que será aquela proveniente da presunção pater is est, biológica, a filiação ligada por laços sanguíneos, e, a socioafetiva, que será a filiação proveniente da natureza afetiva, da posse de estado de filho.

\section{Sociafetividade}

Atualmente, o princípio do afeto é norteador do direito de família, e hoje ultrapassa, em importância, até mesmo a verdade biológica.

A afetividade - cuidada inicialmente pelas ciências sociais, psicologia e educação como objeto de suas ciências - adentrou o direito de família a fim de que pudesse se explicar as relações familiares contemporâneas, tão complexas e multifacetadas. ${ }^{15}$ Tendo como base a afetividade, a parentalidade se mostra como um ato de amor e desapego material, e não simplesmente como fenômeno biológico e científico, surgindo assim a figura da parentalidade socioafetiva. ${ }^{16}$
Tratando do tema "afeto e filiação", é possível resumir que afeto é o cuidado, o carinho, o mimo, o afago estabelecido com outrem, produzindo um profundo sentimento de gostar, de bem-querer alguém. A filiação socioafetiva é o pai ou a mãe que não detém com a criança vínculo consegíneo, mas tem em si como se filho fosse. ${ }^{17}$

Para Rolf Madaleno, "filiação socioafetiva é a real paternidade de afeto e de solidariedade; são gestos de amor que registraram a colidência de interesse entre o filho registral e o seu pai de afeto". ${ }^{18}$

As relações familiares consolidadas no afeto buscam quebrar a ideia de relação parental em que bastava haver ligação consanguínea ou presunção de filiação.

Pode-se referir que não basta ser gerador de um filho, legando sobrenome e material genético, sobressaindo o afeto sobre o vínculo biológico, pois necessário é que exista uma relação filial-afetiva naquele contexto, ${ }^{19}$ ou melhor, o direito deve valorizar

15 LÔBO, Paulo. Direito ao estado de filiação e direito à origem genética. Revista Jus Navigandi, Teresina, ano 9, n. 194, 16 jan. 2004. Disponível em: <http://jus.com.br/ artigos/4752>. Acesso em: 25 abr. 2015

16 VENOSA. Sílvio de Salvo. Op. cit., p. 242.

17 FACHIN, Luiz Edson. Op. cit., p. 100-105.

18 MADALENO, Rolf. Paternidade Alimentar. Revista Brasileira de Direto de Família, ano VIII, n. 37, ago./set. 2006, p. 138.

19 FACHIN, Luiz Edson. Op. cit., p. 18. 
as relações afetivas e amorosas entre pais e filhos, prezando pela veracidade e a autenticidade das relações humanas. $^{20}$

Desse modo, é considerado o estado de filiação não biológico ou socioafetivo aquele entre pai e filho, ou entre mãe e filho, ou entre pais e filho, em que inexiste ligação de ordem sanguínea entre eles, havendo, porém, o afeto como elemento de ligação, a fim de uni-los em suas relações, quer de ordem pessoal, quer de ordem patrimonial. ${ }^{21}$

O pai ou mãe socioafetivo - por este motivo aqui tratamos de parentalidade, e não paternidade - é aquele que a criança realmente identifica como tal figura e que cumpre as funções inerentes para esta criança, que possui também status de filho. ${ }^{22}$

A paternidade é um conceito não só genético ou biológico, mas psicológico, moral e sociocultural. Em grande número de ocasiões o vínculo biológico não transcende a ele mesmo e revela-se completo e patológico fracasso da relação de paternidade, sob o prisma humano, social e ético. Em contrapartida, múltiplas situações de ausência de ligação biológica geram e mostram relação afetiva, em nível de paternidade saudável produtiva, responsável. E os milhões de casos de paternidade biológica não desejada? Por outro lado, a paternidade oriunda da adoção é plenamente consciente e desejada. ${ }^{23}$

A identificação do vínculo de parentesco socioafetivo é de uma filiação psicológica, ou seja, o filho identifica a figura do ente socioafetivo como pai/mãe. Assim, para o bem desta relação, o direito afasta o fator natural e atribui a esta criança um(a) pai/mãe, prestigiando convivência familiar. $^{24}$

Válido mencionar que a filiação socioafetiva não foi especificadamente inserida no ordenamento pátrio, sendo interpretada com base na legislação geral, jurisprudência e doutrina. Assim, procurando uma base legislativa para a filiação socioafetiva, podem ser encontradas concepções de uma filiação desvinculada dos laços

20 WELTER, Belmiro Pedro. Igualdade entre as filiações biológica e socioafetiva. São Paulo: Revista dos Tribunais, 2003. p. 38.

21 FUJITA, Jorge Shiguemitsu; Op. cit., p. 71

22 FACHIN, Luiz Edson. Op. cit, p. 20.

23 PEREIRA, Sérgio Ginschlow apud FACHIN, Luiz Edson. Op. cit., p. 18

24 DIAS, Maria Berenice; Op. cit., p.332. 
sanguíneos no artigos 226, parágrafo $4^{\circ}$, (dignidade de todos os tipos de família), artigo 227, caput, parágrafo $5^{\circ}$ e parágrafo $6^{\circ}$ (igualdade entre filiações, não importando sua origem e direito da criança e do adolescente ao convívio familiar,), e artigos 229 e 230 (imposição da solidariedade a todos os membros da família) todos pertencentes à Constituição Federal. ${ }^{25}$

Na legislação infraconstitucional temos os artigos 1.593 (o qual se refere ao parentesco biológico ou de outra origem), 1596 (igualdade entre as filiações), e 1.597, V (inseminação heteróloga), todos do Código Civil Brasileiro de 2002, e, ainda, artigo 27, do Estatuto da Criança e do Adolescente, o qual trata do direito ao reconhecimento de filiação. ${ }^{26}$

Importante mencionar que a possibilidade de filiação socioafetiva foi consagrada também pela jurisprudência, como pode se verificar nos julgados do Supremo Tribunal Federal, Superior Tribunal de Justiça e tribunais estaduais. $^{27}$

\section{Técnicas e tipos de reprodução assistida}

No que concerne à reprodução assistida é válido referir que existem dois tipos de inseminação: homóloga e heteróloga.

A reprodução assistida homóloga ocorrerá quando existir material genético de ambos os cônjuges ou companheiros, ou seja, quando for utilizado o óvulo do cônjuge virago e o sêmen do cônjuge varão, utilizada quando não é possível a fertilização por meio natural. ${ }^{28}$

Por sua vez, a reprodução assistida será heteróloga quando o material genético fornecido for de um terceiro. Assim, conclui-se que poderá ocorrer vínculo biológico entre todos os cônjuges, nos casos de reprodução homóloga, ou somente a um destes, aquele que fornecer material genético, nos casos de reprodução heteróloga. ${ }^{29}$

Válido referir que a reprodução heteróloga pode ser também em face de um único ente familiar, nos casos

25 LÔBO, Paulo. Direito ao estado de filiação e direito à origem genética. Revista Jus Navigandi, Teresina, ano 9, n. 194, 16 jan. 2004. Disponível em: <http:/jus.com.br/ artigos/4752>. Acesso em: 25 abr. 2015.

26 Ibidem.

27 RIO GRANDE DO SUL. Tribunal de Justiça do Rio Grande do Sul. Apelação Cível n. 70045659554. Relator: Luiz Felipe Brasil Santos. Porto Alegre, RS, 26 de janeiro de 2012. Disponível em: <www. tjrs.jus.br/>. Acesso em: 22 mai. 2015.

28 FUJITA, Jorge Shiguemitsu; Op. cit., p. 67.

29 FUJITA, Jorge Shiguemitsu; Op. cit., p. 67. 
da família monoparental, que é aquela constituída por qualquer um dos pais e seus descendentes, a qual não será aprofundada neste artigo diante da sua própria complexidade, referindo desde logo que pessoas solteiras ou viúvas poderão realizar reprodução heteróloga, conforme Resolução Médica 2013/2013.

Importante mencionar que a reprodução heteróloga é utilizada principalmente nos casos de esterilidade, incompatibilidade do fator Rh, moléstias graves transmissíveis pelo cônjuge entre outros fatores relevantes, ocorrendo, com frequência, o uso de bancos de esperma, em que os doadores são anônimos. ${ }^{30}$

Curioso também mencionar, a fim de que não se deturpe a utilização do termo "inseminação artificial heteróloga”: apesar de constante no Código Civil, houve um equívoco do legislador ao referir apenas sobre a possibilidade de inseminação artificial heteróloga, mesmo com a nítida intenção de abranger o tema Reprodução Assistida, conforme será debatido no momento oportuno.

Apesar de ser a mais conhecida técnica de reprodução assistida, a inseminação artificial não é a única.
Existem outras técnicas de reprodução assistida, tais como: a) fertilização in vitro; b) transferência intratubária de gametas femininos e masculinos; c) transferência intratubária de zigotos nas trompas de falópio; d) Pronuclear Stage Transfer (PROST); e) Tubal Embryo Stage Transfer (TEST); f) inseminação vaginal intratubária; g) inseminação intraperitoneal; h) transferência peritoneal de óvulos e espermatozóides; e, i) extração testicular de espermatozóides. ${ }^{31}$

Dado interessante a ser citado é o número de solicitações feitas ao único Banco de Sêmen de Doadores Anônimos do Brasil, o Hospital Israelita Albert Einstein - que fornece material para todas as cerca de setenta clínicas de reprodução assistida espalhadas pelo país.

Este tem registrado, em média, oitenta pedidos por mês, o que notoriamente é um número de grande expressividade. Cada amostra custa um montante maior do que o salário mínimo nacional, sendo seu valor, em média, de oitocentos reais até mil reais, e apesar do valor nitidamente alto, a procura é de grande demanda. ${ }^{32}$

Ainda que mencionada em nosso Código Civil, tendo sua previsão

30 VENOSA, Sílvio de Salvo. Op. cit., p. 243.

31 FUJITA, Jorge Shiguemitsu. Op. cit., p. 67.

32 CASSETTARI, Christiano. Op. Cit., p. 52. 
expressa somente no Artigo 1.597, V (inseminação artificial heteróloga), bem como no Artigo 1.597, III e IV (reprodução homóloga), a reprodução assistida é uma realidade evidente, que necessita urgentemente de regulamentação, eis que sua menção na norma foi feita de maneira superficial e pouco abrangente.

Além do Código Civil, o único diploma legal que regulamenta as técnicas de reprodução assistida, é a Resolução n. 2013/2013, do Conselho Federal de Medicina (que revogou a Resolução 1.957/2010 e 1.358/92 que também regulavam o tema médico sobre reprodução assistida), a qual trata de temas éticos e toma algumas providências quanto a regulamentação de clínicas de reprodução assistida e bancos de sêmen.

A referida Resolução também é responsável por normatizar a forma como ocorrerá a doação de gametas e embriões, incluindo previsões de caráter ético sobre registros anônimos de doação e responsabilidade das clínicas. ${ }^{33}$
Segundo a mesma, os doadores não devem conhecer a identidade dos receptores e sequer os receptores poderão ter acesso a identidade dos doadores, sendo obrigatório o sigilo sobre a identidade dos doadores de gametas e embriões, bem como dos receptores. ${ }^{34}$

Existe a previsão, contudo, de que em situações especiais e somente por motivação exclusivamente médica, as informações sobre doadores podem ser fornecidas exclusivamente para médicos, os quais repassariam tais informações, resguardando-se sempre a identidade civil do doador. ${ }^{35}$ Tanto ou mais necessária tal regulamentação em casos reprodução artificial heteróloga, que apesar da presunção de paternidade presumida na legislação, tendem a formar laços familiares de maior complexidade do que a reprodução assistida homóloga. Isto porque pelo menos um dos materiais genéticos será de terceiro, acabando por criar verdadeiras dúvidas quanto à parentalidade e suas consequências no caso concreto, al-

33 CASSETTARI, Christiano. Op. Cit., p. 53.

34 ITEM 2: Os doadores não devem conhecer a identidade dos receptores e vice-versa. 35 ITEM 3: Obrigatoriamente será mantido o sigilo sobre a identidade dos doadores de gametas e embriões, bem como dos receptores. Em situações especiais, as informações sobre doadores, por motivação médica, podem ser fornecidas exclusivamente para médicos, resguardando-se a identidade civil do doador. 
cançando o judiciário sem maiores embasamentos legislativos, conforme será demonstrado.

\section{Aspectos jurídicos da reprodu- ção assistida heteróloga}

Na amplitude de técnicas de reprodução assistida já mencionadas, poderão ocorrer técnicas heterólogas, nas quais se necessita da doação de material genético de um terceiro.

A reprodução assistida heteróloga poderá ser unilateral, quando o material genético for de somente um dos cônjuges, pai ou mãe biológico, sendo o outro fornecido por doador anônimo, ou bilateral, quando ocorrer a doação integral de material genético de terceiros, ou seja, nenhum dos cônjuges detém vínculo biológico, servindo o ventre da cônjuge somente como gerador da criança. ${ }^{36}$

Geralmente é indicada a casais em que ocorra absoluta esterilidade masculina, doenças genéticas graves ou ainda incompatibilidade do tipo sanguíneo do casal. ${ }^{37}$

Não é necessário, entretanto, que o cônjuge não doador seja estéril ou não possa procriar por qualquer outra razão. ${ }^{38}$

A filiação proveniente da reprodução assistida heteróloga tem previsão legal no artigo 1.597, V, do Código Civil, apesar de que em tal dispositivo conste somente uma das técnicas de reprodução assistida, a inseminação artificial heteróloga. Esta ocorrerá quando é utilizado sêmen de outro homem, normalmente um doador anônimo, para a fecundação do óvulo da mulher. ${ }^{39}$

Todavia, apesar de não constar expressamente descrito em lei, a relação filial-paternal, proveniente da inseminação heteróloga unilateral, não ocorre somente através do cônjuge varão, podendo existir reprodução heteróloga mediante doação de um óvulo que não seja o da esposa, com a fecundação do sêmen do marido. ${ }^{40}$

36 FUJITA, Jorge Shiguemitsu. Op. cit., p. 67.

37 RIZZARDO, Arnaldo. Op. cit., p. 438.

38 LÔBO, Paulo. Direito ao estado de filiação e direito à origem genética. Revista Jus Navigandi, Teresina, ano 9, n. 194, 16 jan. 2004. Disponível em: <http://jus.com.br/ artigos/4752>. Acesso em: 25 abr. 2015

39 LÔBO, Paulo. Ibidem.

40 RIZZARDO, Arnaldo. Op. cit., p. 351.

41 FUJITA, Jorge Shiguemitsu. Op. cit., p. 68. 
Resumidamente, pode-se referir que, na reprodução humana assistida heteróloga unilateral, biologicamente falando, um dos cônjuges ou um dos companheiros será, efetivamente, pai biológico ou mãe biológica, enquanto o outro será pai socioafetivo ou mãe socioafetiva, por não ter participado com seu elemento genético. ${ }^{41}$

Poderá, entretanto, inexistir ligação biológica entre os pais e o filho, na hipótese de reprodução assistida heteróloga bilateral, na qual os materiais genéticos foram fornecidos por um doador e uma doadora anônimos, com a gestação no útero da esposa ou da companheira. ${ }^{42}$

O material genético do terceiro, com o qual virá a ser gerado o filho, será colhido por meio de um banco de material. Durante a seleção dos doadores é realizado um controle periódico do material para descobrir possíveis doenças, bem como são colhidas informações sobre características morfológicas do doador, grupo sanguíneo, cor da pele e dos olhos, estatura, procurando a maior compatibilidade possível com o casal. ${ }^{43}$
Importante mencionar que as normas regentes do instituto da adoção podem ser utilizadas para a procriação assistida heteróloga, entre elas o desligamento do vínculo de parentesco com os geradores, os impedimentos matrimoniais entre filhos e pais/mães socioafetivos, entre outras pertinentes ao caso concreto que for apresentado. ${ }^{44}$

\section{a) Presunção proveniente do consentimento}

Para que ocorra o procedimento de reprodução assistida heteróloga é exigência que haja consentimento do cônjuge não doador. Com tal consentimento, se estabelece uma presunção de paternidade ou de maternidade daquele cônjuge que não fornecer material genético.

Tal previsão consta no Código Civil, nos casos de inseminação artificial, em que se exige o consentimento expresso do marido, a fim de que ali se presuma uma paternidade: "havidos por inseminação artificial heteróloga, desde que tenha prévia autorização do marido". ${ }^{45}$

42 FUJITA, Jorge Shiguemitsu. Op. cit., p. 68.

43 RIZZARDO, Arnaldo. Op. cit., p. 438.

44 DIAS, Maria Berenice. Op. cit., p. 340.

45 Artigo 1597, V, do Código Civil: "Presumem-se concebidos na constância do casamento os filhos: V. havidos por inseminação artificial heteróloga, desde que tenha prévia autorização do marido”.

46 CASSETTARI, Christiano; Op. cit., p. 152. 
Ressalta-se que, conforme já das pessoas submetidas às técnicas mencionado, apesar do artigo 1.597, de reprodução assistida, ressaltando, V, do Código Civil citar expressamen- novamente, a necessidade de exte a inseminação artificial heteróloga, não tratando de outras técnicas de reprodução assistida, tal circunstância não passou de um descuido do legislador, eis que a norma é utilizada amplamente para regulamentar todas as formas de reprodução assistida.

Inclusive, já se manifestou o CJF, em seu Enunciado n. 105, que procurou reparar as imprecisões técnicas constantes no Artigo 1.597 e seus incisos, referindo que, as expressões fecundação artificial, concepção artificial e inseminação artificial, constantes nos incisos III, IV, V, na realidade, deverão ser interpretadas como "técnicas de reprodução assistida. ${ }^{46}$

Ainda, a própria Resolução n. 1.957/2010 j7 já previa (posteriormente revogada pela Resolução n. 2013/ 2013, do Conselho Federal de Medicina), em seu anexo único de normas éticas, item 3 , o consentimento presso consentimento de todos os envolvidos, incluindo o cônjuge não doador.

Apesar da omissão legislativa, compreende-se que tal presunção também atingirá a maternidade, nos casos em que se dê a reprodução assistida heteróloga por doador com o uso de gameta (semêm) do esposo e gameta (óvulo) de doadora anônima, com a anuência prévia da esposa, existindo uma consolidação da presução iuris et de iure de maternidade socioafetiva. ${ }^{48}$

Caso não existisse a presunção também quanto ao cônjuge virago, certamente restaria violada a norma constitucional que iguala homens e mulheres, afinal, se existe a presunção quanto ao cônjuge varão, necessário que se dê o mesmo tratamento ao cônjuge virago, que não doará material genético (óvulo), mas gerará o filho em seu ventre. ${ }^{49}$

47 Item 3. O consentimento informado será obrigatório a todos os pacientes submetidos às técnicas de reprodução assistida, inclusive aos doadores. Os aspectos médicos envolvendo as circunstâncias da aplicação de uma técnica de reprodução assistida serão detalhadamente expostos, assim como os resultados obtidos naquela unidade de tratamento com a técnica proposta. As informações devem também atingir dados de caráter biológico, jurídico, ético e econômico. O documento de consentimento informado será expresso em formulário especial e estará completo com a concordância, por escrito, das pessoas submetidas às técnicas de reprodução assistida.

48 FUJITA, Jorge Shiguemitsu. Op. cit., p. 77.

49 Existe também a possibilidade de gestação de “útero emprestado”, também chamada vulgarmente de barriga de aluguel, a qual não será tratada neste artigo, uma vez que se 
Pode-se referir que, devido à presunção de paternidade constante no Código Civil, surge a figura da filiação jurídica ao cônjuge não doador nos casos de inseminação artificial heteróloga, ou seja, a filiação imputada pela própria legislação. Importante mencionar que se soma ao aspecto jurídico o aspecto socioafetivo, não se falando em uma filiação em detrimento de outra. ${ }^{50}$

Diante desta necessidade de existir a vontade de ser pai ou mãe que se faz necessário o consentimento. Sem tal consentimento, impossível que se admita a presunção de paternidade em tal situação.

Afinal, caso efetivasse uma reprodução assistida sem o consentimento do cônjuge não doador, o cônjuge com vínculo biológico acabaria por romper deveres advindos do casamento, bem como estaria nítida a inexistência de comprovação do querer ser pai/mãe, a fim de realizar vínculo socioafetivo com o ser concebido, podendo até mesmo o cônjuge omitir a verdade biológica sobre a filiação, não passando toda a situação de uma verdadeira fraude. ${ }^{51}$

Caso se criasse um vínculo socioafetivo entre o ente parental e a criança, mediante convivência, este poderia ser posteriormente preservado, todavia, não há que se falar em presunção de paternidade/maternidade.

NEGATÓRIA DE PATERNIDADE. NULIDADE DO REGISTRO DE NASCIMENTO. ALEGAÇÃO DE INDUÇÃO EM ERRO. INSEMINAÇÃO ARTIFICIAL HETERÓLOGA. LEGITIMIDADE ATIVA DOS HERDEIROS COLATERAIS. Legitimidade ad causam de quem tenha legítimo interesse moral ou material na declaração da nulidade do registro de nascimento. Ação que tem por base erro em que o pai foi induzido ao registrar o filho que pensava ser fruto de inseminação artificial heteróloga. Necessidade de se permitir o prosseguimento do feito, para eventual produção de prova do vínculo afetivo. Inexistência de prescrição. Sentença cassada. APELO PROVIDO PARA DETERMINAR PROSSEGUIMENTO DO FEITO. (SEGREDO DE JUSTIÇA) (RIO

trata de problemática à parte, além de não ser, necessariamente, por reprodução heteróloga, podendo existir casos de reprodução homóloga, quando o problema de reprodução do casal se dá, unicamente, no útero da mulher.

50 LÔBO, Paulo. Direito ao estado de filiação e direito à origem genética. Revista Jus Navigandi, Teresina, ano 9, n. 194, 16 jan. 2004. Disponível em: <http://jus.com.br/ artigos/4752>. Acesso em: 25 abr. 2015

51 RIZZARDO, Arnaldo. Op. cit., p. 451. 
GRANDE DO SUL, Apelação Cível n. 70011878899, Relatora Maria Berenice Dias, 2005.)

Importante mencionar que a presunção de paternidade (ou de maternidade, eis que conforme já mencionado, a mulher poderá ser o cônjuge não doador de material genético) está normatizada somente para o casamento. Desse modo, questiona-se quanto à possibilidade de extensão da presunção constante no Código Civil, no que se refere à inseminação artificial heteróloga, para fins de união estável.

A possibilidade de extensão da presunção constante no artigo 1.597 do Código Civil para as relações de união estável é bem aceita pela jurisprudência, constando inúmeros julgados quanto a equiparação da união estável ao casamento para fins de presunção de filiação, sob a argumentação de que dessa forma, tanto o texto constitucional, em seu art. 226,§ $3^{\circ}$, bem como o Código Civil em seu art. 1.723 conferiram ao instituto da união estável proteção de natureza familiar, de modo que não seria razoável interpretar o artigo de maneira literal.

Afinal, se tratando de união estável, estão presentes todos os requisitos semelhantes ao instituto do casamento, tais como dever de lealdade, estabilidade, entre outros necessários para que se presuma a paternidade/ maternidade da criança concebida por reprodução assistida heteróloga.
Nesse sentido, inclusive, já se manifestou o Superior Tribunal de Justiça, em decisão que cumpre transcrever:

Assim, se nosso ordenamento jurídico, notadamente o próprio texto constitucional (art. 226, $\S 3^{\circ}$ ), admite a união estável e reconhece nela a existência de entidade familiar, nada mais razoável de se conferir interpretação sistemática ao art. 1.597, II, do Código Civil, para que passe a contemplar, também, a presunção de concepção dos filhos na constância de união estável. V. Na espécie, o companheiro da mãe da menor faleceu 239 (duzentos e trinta e nove) dias antes ao seu nascimento. Portanto, dentro da esfera de proteção conferida pelo inciso II do art. 1.597 do Código Civil, que presume concebidos na constância do casamento os filhos nascidos nos trezentos dias subsequentes, entre outras hipóteses, em razão de sua morte. VI. Dessa forma, em homenagem ao texto constitucional (art. 226, § $3^{\circ}$ ) e ao Código Civil (art. 1.723), que conferiram ao instituto da união estável a natureza de entidade familiar, aplica-se as disposições contidas no artigo 1.597, do Código Civil, ao regime de união estável (BRASIÍLIA, Superior Tribunal de Justiça, REsp: 1194059 SP 2010/0085808-2, Relator: Ministro Massami Uyeda, 2012).

No que tange ao consentimento do cônjuge para a realização da reprodução assistida, importante mencionar que ainda existem divergências doutrinárias de como se deve realizar tal consentimento, ou seja, se este de- 
verá ser realizado verbalmente ou por escrito, mediante documento público ou particular.

Para Maria Berenice Dias, este consentimento não precisa, necessariamente, ser por escrito, podendo ser verbal e posteriormente ser comprovado em juízo, mas é imprescindível ser prévio à inseminação, pois desde que dada à autorização para o procedimento é que se cria um vínculo socioafetivo com o filho. ${ }^{52}$

Sob o mesmo prisma, Paulo Luiz Netto Lôbo e Luís Paulo Cotrim Guimarães, ${ }^{53}$ entendem também pela possibilidade da declaração de vontade - consentimento - verbal do cônjuge ou companheiro para fins de reprodução assistida heteróloga. Por outro lado, Carlos Eduadrdo Nicoletti Camillo e Jorge Shiguemitsu Fujita ${ }^{54}$ compreendem pela necessidade de ser escrito tal consentimento, o primeiro através de instrumento público, enquanto o segundo doutrinador compreende pela simples escrita de documento particular.

É unânime, contudo, que tal consentimento é irretratável, não podendo o cônjuge que teve conhecimento, e por óbvio consentiu na reprodução assistida com doação de material genético de terceiro, depois, impugnar a paternidade, sob a argumentação de que não detém vínculo biológico com a criança.

Afinal, por meio da reprodução heteróloga, além da filiação jurídica imputada ao cônjuge não doador que deu seu consentimento expresso, nasce o vínculo socioafetivo entre pai/mãe não doador, seja de maneira unilateral ou bilateral, pois foi através da vontade destes de ser pai/mãe que foi possibilitado o nascimento de uma criança, existindo este vínculo entre os pais socioafetivos e o filho desde o momento da concepção.

O Direito Comparado também afirma sobre a impossibilidade de retratação do cônjuge que deu seu consentimento para a realização de reprodução assistida. Nos Estados Unidos, o Uniform Parantage Act, de 1973 e 1987, estabelece que se sob supervisão médica e com o consentimento do marido, a mulher for inseminada artificialmente com sêmen de doador, o marido é considerado como o pai natural da criança, mencionando, ainda, que o consentimento deve ser escrito por ambos os cônjuges, enquanto o art. 311-20 do Código Civil francês normatiza que o consentimento dado

52 DIAS, Maria Berenice; Op. cit., p. 338.

53 FUJITA, Jorge Shiguemitsu. Op. cit., p.73. 54 Ibidem. 
proíbe toda ação de contestação ao estado de filiação A justiça italiana também decidiu que o marido que tenha manifestado prévio consentimento à fecundação heteróloga não tem ação para contestar a paternidade da criança nascida em decorrência de tal fecundação. ${ }^{55}$

Valioso referir que a tutela deste tipo de concepção fortalece a natureza socioafetiva, e não biológica, da filiação e da parentalidade, uma vez que se o cônjuge autorizou tal procedimento, não poderá se negar, posteriormente, em razão da origem genética, de exercer o papel de pai/mãe da criança gerada. ${ }^{56}$

Sequer poderá ser admitida a possibilidade de o(a) pai/mãe que deu seu consentimento para a reprodução assistida mover ação negatória de paternidade, sob o fundamento de arrependimento posterior ou até mesmo contestando o vínculo biológico, conforme enunciado n. 258 da III Jornada de Direito Civil. Qualquer contestação de paternidade (ou maternidade) ocasionaria um verdadeiro venire contra factum proprium, entre a contradição direta entre a autorização dada e a segunda conduta. ${ }^{57}$

\section{b) Possibilidade de investigação de paternidade para fins de busca de origem genética}

A Resolução n. ${ }^{0}$ 2013/2013, do Conselho Federal de Medicina, regulamenta sobre o sigilo e sobre a atualização de dados dos doadores e receptores. Tal Resolução refere que as clínicas e os centros ou serviços que empregam a doação devem manter permanentemente um registro de dados clínicos com informações gerais, danos fenotípicos e amostra de material.

Uma vez que a doação é anônima, os dados fornecidos pelos doadores serão obrigatoriamente mantidos em sigilo absoluto, ou seja, os receptores não terão acesso sobre a identidade dos doadores de gametas e embriões, e vice-versa.

Somente em situações especiais, a resolução prevê que as clínicas forneçam as informações necessárias sobre doadores, exclusivamente por moti-

55 LÔBO, Paulo. Direito ao estado de filiação e direito à origem genética. Revista Jus Navigandi, Teresina, ano 9, n. 194, 16 jan. 2004. Disponível em: <http://jus.com.br/ artigos/4752>. Acesso em: 25 abr. 2015.

56 Ibidem.

57 FUJITA, Jorge Shiguemitsu. Op. cit., p. 78. 
vações médicas, dados estes que serão igualmente fornecidos somente para médicos, resguardando-se a identidade civil do doador. Tal disposição de anonimato e sigilo de informações também era prevista na Resolução 1.358 de 1992, revogada pela Resolução 1.957 de 2010, também revogada pela Resolução 2013 de 2013.

Pode se referir que tais disposições visam o incentivo das técnicas de reprodução assistida, a fim de que seja preservado o anonimato dos doadores, bem como de que seja garantida a autonomia e o desenvolvimento normal da família receptora do material genético. ${ }^{58}$

Claramente é necessário o anonimato em técnicas de reprodução assistida em que se doe material genético, afinal, sem este, não haveria como se realizar a doação, por questões éticas, eis que o doador de material genético não visa constituir família, sendo sua doação somente realizada por altruísmo, devendo ser levada em consideração a sua vontade, já que, sem ele jamais teria sido gerada a criança, ${ }^{59}$ além do dever de se respeitar o regulamento da resolução médica.

Todavia, chega-se a uma problemática: teria o fruto da reprodução heteróloga direito a ajuizar ação de investigação de paternidade ou maternidade, a fim de conhecer sua verdadeira origem biológica?

Valioso referir que não se fala em ajuizar tal ação com o pleito de constituir uma filiação biológica com o doador de material genético. Tal fato se tornaria impossível e é amplamente rechaçado, até mesmo pela presunção contida no Código Civil, bem como pela filiação socioafetiva já instaurada com o cônjuge que não doou material genético. Caso existisse a possibilidade de questionar a paternidade/ maternidade, no caso de reprodução artificial heteróloga, haveria uma paternidade/maternidade incerta, tendo em vista o anonimato do doador. ${ }^{60}$

Muito se discute acerca da possibilidade do filho fruto de inseminação artificial heteróloga buscar sua origem genética através da investigação de paternidade/maternidade. Não existindo nenhuma ação própria,

58 FUJITA, Jorge Shiguemitsu. Op. cit., p. 76.

59 Martinelli, Lorhainy Ariane Lagassi. Aspectos jurídicos do anonimato do doador de sêmen na reprodução humana heteróloga. Disponível em: <http://www.ambito-juridico.com.br/site/index.php?n_link=revista_artigos_leitura\&artigo_id=10916>. Acesso em: 22 mai. 2015

60 DINIZ, Maria Helena. Curso de Direito Civil Brasileiro. v. 5. São Paulo: Saraiva, 2002. p. 380. 
que não esta, para que se busque judicialmente a origem do doador, é comum que venha a discussão da possibilidade de utilização do meio da investigação de paternidade para tanto. Afinal, a busca pela origem genética trata-se de direito de personalidade inerente à criança, e a ação de investigação de paternidade ou maternidade parece ser, em um primeiro momento, a melhor forma de levar tal assunto ao judiciário.

Arnaldo Rizzardo defende pela impossibilidade da utilização do meio de investigação de paternidade ou maternidade para fins de descoberta da origem genética, sob o argumento de que desde que assumida a paternidade ou até a maternidade, vindo o filho de produção heteróloga, necessário que se dissocie por completo dos fornecedores do esperma ou óvulo, pois o vínculo parental ali formado não é mais um fato natural, e sim fundado na vontade, ou seja, não existirá direito de ação no caso. ${ }^{61}$

Eduardo Leite ${ }^{62}$ compreende que o fato de revelar sua origem genética à criança não acrescenta em nada sua filiação, enquanto Gustavo Tepedino ${ }^{63}$ compreende que a descoberta pela verdade científica pode vir a ser sacrificada em nome do melhor interesse da criança, diante das normas que regem a filiação.

Por outro lado, Maria Berenice Dias e Jorge Shiguemitsu Fujita compreendem pela possibilidade da utilização do meio de investigação de paternidade, para que possa o filho ter acesso à sua origem biológica. ${ }^{64}$

Com razão, Paulo Lobo ao se referir que para garantir a tutela do direito de personalidade, ou seja, ao direito de verificar a origem genética, não há necessidade de investigar a paternidade:

O objeto da tutela do direito ao conhecimento da origem genética é assegurar o direito da personalidade, na espécie direito à vida, pois os dados da ciência atual apontam para a necessidade de cada indivíduo saber a história de saúde de seus parentes biológicos próximos para a prevenção da própria vida. Não há necessidade de se atribuir a paternidade a alguém para se ter o direito da personalidade de conhecer, por exemplo, os ascendentes biológicos paternos do que foi gerado por doador anônimo de sêmen, ou do que foi adotado, ou do que foi concebido por inseminação artificial heteróloga. Toda pessoa

61 RIZZARDO, Arnaldo. Op. cit., p. 454.

62 FUJITA, Jorge Shiguemitsu. Op. cit., p. 78.

63 Ibidem.

64 Ibidem. 
tem direito fundamental, na espécie direito de personalidade, de vindicar sua origem biológica para que, identificando seus ascendentes genéticos, possa adotar medidas preventivas para preservação da saúde e, a fortio$r i$, da vida. Esse direito é individual, personalíssimo, não dependendo de ser inserido em relação de família para ser tutelado ou protegido. Uma coisa é vindicar a origem genética, outra a investigação da paternidade. A paternidade deriva do estado de filiação, independentemente da origem (biológica ou não). ${ }^{65}$

Afinal, apesar de sustentar o direito à identidade genética, até mesmo para questões que envolvam a saúde da criança, não há que se confundir a investigação de paternidade (maternidade), a qual visa investigar a paternidade (ou maternidade, como poderá oportunamente ocorrer) com o direito de personalidade, o qual poderá ser buscado de outras maneiras, mesmo diante da ausência de ação específica no âmbito do direito de família para tutelar tal questão.

No mesmo sentido foi julgada recente ação no Tribunal de Justiça do
Rio grande do Sul, em que houve a compreensão de que quebrar o anonimato sobre o doador anônimo no caso de inseminação artificial heteróloga inviabilizaria a utilização da própria técnica de inseminação, eis que acabaria com os interessados em realizar tal ato, eis que conclusão lógica da doação anônima o fato de que quem doa não deseja ser identificado e tampouco desejaria ser responsabilizado pela paternidade ou maternidade de uma criança gerada através de seu material genético, mesmo que tal fato se contraponha ao direito indisponível e imprescritível de reconhecimento do estado de filiação. ${ }^{66}$

AGRAVO DE INSTRUMENTO. PEDIDO DE REGISTRO DE NASCIMENTO DEDUZIDO POR CASAL HOMOAFETIVO, QUE CONCEBEU O BEBÊ POR MÉTODO DE REPRODUÇÃO ASSISTIDA HETERÓLOGA, COM UTILIZAÇÃO DE GAMETA DE DOADOR ANÔNIMO. DECISÃO QUE ORDENOU A CITAÇÃO DO LABORATÓRIO RESPONSÁVEL PELA INSEMINAÇÃO E DO DOADOR ANÔNIMO, BEM COMO NO-

65 LÔBO, Paulo. Direito ao estado de filiação e direito à origem genética. Revista Jus Navigandi, Teresina, ano 9, n. 194, 16 jan. 2004. Disponível em: <http://jus.com.br/ artigos/4752>. Acesso em: 25 abr. 2015.

66 Agravo de Instrumento n. 70052132370, Oitava Câmara Cível, Tribunal de Justiça do RS, Relator: Luiz Felipe Brasil Santos, Julgado em: 04/04/2013. Disponível em: $<$ http://www.tjrs.jus.br >. Acesso em: 25 abr. 2015. 
MEOU CURADOR ESPECIAL À INFANTE. DESNECESSÁRIO TUMULTO PROCESSUAL. INEXISTÊNCIA DE LIDE OU PRETENSÃO RESISTIDA. SUPERIOR INTERESSE DA CRIANÇA QUE IMPÕE O REGISTRO PARA CONFERIR-LHE O STATUS QUE JÁ DESFRUTA DE FILHA DO CASAL AGRAVANTE, PODENDO OSTENTAR O NOME DA FAMÍLIA QUE LHE CONCEBEU. 1. Por tratar-se de um procedimento de jurisdição voluntária, onde sequer há lide, promover a citação do laboratório e do doador anônimo de sêmen, bem como nomear curador especial à menor, significaria gerar um desnecessário tumulto processual, por estabelecer um contencioso inexistente e absolutamente desarrazoado. 2 . Quebrar o anonimato sobre a pessoa do doador anônimo, ao fim e ao cabo, inviabilizaria a utilização da própria técnica de inseminação pela falta de interessados. É corolário lógico da doação anônima o fato de que quem doa não deseja ser identificado e nem deseja ser responsabilizado pela concepção havida a partir de seu gameta e pela criança gerada. Por outro lado, certo é que o desejo do doador anônimo de não ser identificado se contrapõe ao direito indisponível e imprescritível de reconhecimento do estado de filiação, previsto no art. 22 do ECA. Todavia, trata-se de direito personalíssimo, que somente pode ser exercido por quem pretende investigar sua ancestralidade - e não por terceiros ou por atuação judicial de ofício. 3. Sendo oportunizado à menor o exercício do seu direito personalíssimo de conhecer sua ancestralidade biológica mediante a manutenção das informações do doador junto à clínica responsável pela geração, por exigência de normas do Conselho Federal de Medicina e da Agência Nacional de Vigilância Sanitária, não há motivos para determinar a citação do laboratório e do doador anônimo para integrar o feito, tampouco para nomear curador especial à menina no momento, pois somente a ela cabe a decisão de investigar sua paternidade. 4. O elemento social e afetivo da parentalidade sobressai-se em casos como o dos autos, em que o nascimento da menor decorreu de um projeto parental amplo, que teve início com uma motivação emocional do casal postulante e foi concretizado por meio de técnicas de reprodução assistida heteróloga. Nesse contexto, à luz do interesse superior da menor, princípio consagrado no art. 100, inciso IV, do ECA, impõe-se o registro de nascimento para conferir-lhe o reconhecimento jurídico do status que já desfruta de filha do casal agravante, podendo ostentar o nome da família que a concebeu. DERAM PROVIMENTO. UNÂNIME. (Agravo de Instrumento n. 70052132370, Oitava Câmara Cível, Tribunal de Justiça do RS, Relator: Luiz Felipe Brasil Santos, Julgado em: 04/04/2013) (TJ-RS - AI: 70052132370 RS , Relator: Luiz Felipe Brasil Santos, Data de Julgamento: 04/04/2013, Oitava Câmara Cível, Data de Publicação: Diário da Justiça do dia 09/04/2013)

Ainda, relatou o acórdão também no sentido de que está sendo oportunizado à criança o exercício do seu direito à origem biológica por meio da manutenção das informações do 
doador junto à clínica responsável pela geração, obrigatória por exigência de normas do Conselho Federal de Medicina e da Agência Nacional de Vigilância Sanitária, ou seja, estaria resguardado seu direito. ${ }^{67}$

Compreende-se que até mesmo diante da necessidade das Clínicas manterem os dados atualizados dos doadores, guardando informações médicas relevantes e amostras de material genético, bem como possibilitando o acesso de tais informações através de requerimento médico, resta assegurado o direito à origem genética, sem a necessidade de se recorrer a uma ação de investigação de paternidade ou de maternidade, que seria um meio no mínimo inadequado para se buscar tais informações.

\section{CONCLUSÃO}

Entre as profundas modificações no que tange ao tratamento dos filhos após a promulgação da Constituição Federal de 1988, a reprodução assistida heteróloga, unilateral ou bilateral, se trata de excelente avanço científico, o qual proporciona que pessoas com casos de esterilidade, incompatibilidade do fator Rh, moléstias graves transmissíveis pelo cônjuge entre outros fatores relevantes, possam construir vínculos de filiação, e até mesmo gerar um filho, merecendo, assim, destaque em nosso ordenamento jurídico.

Bancos de esperma, em que os doadores são anônimos, estão cada vez mais frequentes, de modo que, diante do aumento da procura por este tipo de reprodução, bem como sua nítida importância social, necessário que o sistema jurídico desenvolva melhor o tema, eis que fraca a legislação sobre o assunto, que se resume em alguns artigos do Código Civil, tratados neste trabalho, e na atual Resolução Médica 2013/2013.

Aspectos como a possibilidade de investigação de paternidade para fins de busca de origem genética ou a presunção de parentalidade restam ainda controversos, utilizando-se, por vezes, unicamente de entendimento jurisprudencial e doutrinário para serem solucionados, mesmo após treze anos de vigência do Código Civil, necessitando ainda, utilizar institutos da adoção para regulamentar a procriação assistida heteróloga.

67 Ibidem. 


\section{REFERÊNCIAS}

BOEIRA. José Bernardo Ramos. Investigação de Paternidade. Posse de Estado de Filho: Paternidade Socioafetiva. Porto Alegre: Livraria do Advogado, 1999.

CASSETTARI, Christiano. Multiparentalidade e Parentalidade Socioafetiva: efeitos jurídicos. 2. ed. São Paulo: Atlas, 2015.

DIAS, Maria Berenice. Manual de Direito das Famílias. Porto Alegre: Livraria do Advogado, 2005. DINIZ, Maria Helena. Curso de Direito Civil Brasileiro. v. 5. São Paulo: Saraiva, 2002.

FACHIN, Luiz Edson. Elementos Críticos de Direito de Família. Rio de Janeiro: Renovar, 2003.

GONZALES, África; DIAS, Maria Berenice (coord.). Afeto, Ética, Família e o Novo Código Civil. Belo Horizonte: Del Rey, 2004.

FUJITA, Jorge Shiguemitsu. Filiação. São Paulo: Atlas, 2011.

LÔBO, Paulo. Direito ao estado de filiação e direito à origem genética. Revista Jus Navigandi, Tere- sina, ano 9, n. 194, 16 jan. 2004.

Disponível em: <http://jus.com. br/artigos/4752>. Acesso em: 25 abr. 2015

MADALENO, Rolf. Paternidade Alimentar. Revista Brasileira de Direto de Família, ano VIII, n. 37, ago./set. 2006.

MARTINELLI, Lorhainy Ariane Lagassi. Aspectos jurídicos do anonimato do doador de sêmen na reprodução humana heteróloga. Disponível em: <http://www. ambitojuridico.com.br/site/index. php?n_link=revista_artigos_ leitura\&artigo_id=10916>. Acesso em: 22 mai. 2015.

RIZZARDO, Arnaldo. Direito de Família. Rio de Janeiro: Forense, 2011.

WELTER, Belmiro Pedro. Igualdade entre as filiações biológica e socioafetiva. São Paulo: Revista dos Tribunais, 2003.

VENOSA. Sílvio de Salvo. Direito Civil: direito de família. São Paulo: Atlas, 2008. 